УДК $621.314 .212-048.24$

Пахомов С. Н., Потапов А. М., Резниченко В. И., Мостипан С. Е.

Государственное предприятие «Конструкторское бюро «Южное» им. М. К. Янгеля» .

Украина, г. Днепр

\title{
ИСПЫТАНИЯ СИСТЕМЫ ЗАЩИТЫ \\ МАСЛОНАПОЛНЕННЫХ ТРАНСФОРМАТОРОВ ТОКА ОТ ВОЗДЕЙСТВИЯ ДУГОВОГО РАЗРЯДА ПРИ КОРОТКОМ ЗАМЫКАНИИ ЭНЕРГИЕЙ ВЗРЫВА
}

Рассмотрены результаты испытаний высоковольтных измерительных трансформаторов тока ТФРМ с разгрузочными клапанами и усиленной фарфоровой покрышкой, в которых в качестве внутренней изолящии используется трансформаторное масло, при помощи подрыва навески взрывчатого вещества имитирующего короткое замыкание внутри трансформатора тока. [dx.doi.org/10.29010/081.2]

Ключевые слова: маслонаполненный трансформатор тока; взрывозащищенность; разгрузочная мембрана.

Актуальность и постановка проблемы

Важнейшими задачами при строительстве и техническом перевооружении электрических подстанций являются повышение надежности, автоматизации и снижение эксплуатационных расхо- дов, применение усовершенствованных видов оборудования, в том числе трансформаторов и автотрансформаторов с повышенной надежностью вводов, необходимой динамической стойкостью и низкими потерями, а также системами предотвращения взрыва и пожаротушения. 
Анализ повреждаемости парка трансформаторов и автотрансформаторов классов напряжения 110-500 кВ мощностью 63 МВ·А и более, эксплуатируемых на предприятиях электрических сетей показывает, что удельное количество технологических нарушений в работе указанных трансформаторов, приведших к их отключению действием автоматических защитных устройств или вынужденному отключению персоналом по аварийной заявке, составляет более 1,8 \% в год. При этом более $30 \%$ от общего числа этих технологических нарушений сопровождались возникновением внутренних коротких замыканий в трансформаторе [1, с. 9-14].

Основными причинами технологических нарушений, сопровождавшихся внутренним коротким замыканием в маслонаполненных трансформатоpax тока, являются (в \% от общего количества повреждений трансформаторов, сопровождающихся внутренними короткими замыканиями):

- пробой внутренней изоляции высоковольтных вводов $\approx 48 \%$;

- недостаточная стойкость при коротких замыканиях $\approx 14 \%$;

- износ изоляции обмоток $\approx 12 \%$;

- пробой изоляции обмоток $\approx 7 \%$;

- пробой изоляции отводов, нарушения контактного соединения отвода обмотки, обрыв части проводников гибкой связи, замыкание на ярмовую балку магнитопровода в корпусе бака и др.

Взрывы высоковольтного маслонаполненного электротехнического оборудования (ВМЭО) происходят, как правило, в процессе развития дугового разряда при внутреннем коротком замыкании. Начальный проводящий канал в трансформаторном масле образуется обычно вследствие постепенной деградации внутренней изоляции при возникновении и развитии в ней частичных разрядов. Дуговой разряд горит десятки миллисекунд, пока не сработают защитные устройства. Энергия дугового разряда может составлять от нескольких десятых долей мегаджоуля в измерительных трансформаторах до нескольких десятков мегаджоулей в силовых трансформаторах.

При дуговом разряде происходит интенсивное разложение трансформаторного масла с выделением большого объема газов, что приводит к значительному росту давления в месте возникновения короткого замыкания и распространению от него интенсивных волн давления внутри ВМЭО. Все это заканчивается зачастую взрывным разрушением корпуса ВМЭО. В случае попадания воздуха в парогазовую смесь продуктов разложения трансформаторного масла, вышедших наружу из разрушенного корпуса ВМЭО, может произойти воспламенение образовавшейся смеси.

Из имеющих место повреждений с внутренними короткими замыканиями в 24\% случаев имели место возгорания и пожары трансформаторов. При этом удельная повреждаемость силовых трансформаторов и автотрансформаторов напряжением 110-500 кВ мощностью 63 МВ·А и более, эксплуатируемых на предприятиях электрических и межсистемных сетей, сопровождающихся внутренними короткими замыканиями, составляет $\approx 0,45 \%$ в год [1, с. 19-20].

Аварийность измерительных трансформаторов составляет $10 \%$ от общего числа технологических нарушений. При этом удельное количество технологических нарушений, сопровождающихся взрывами и пожаром, составляет 0,2 \%.

Внутреннее короткое замыкание в аппарате, которое может возникнуть в процессе эксплуатации измерительных трансформаторов серии ТФРМ, вызывает взрыв трансформатора с пожаром и с разбросом частей аппарата на расстояние более 100 м, что приводит к повреждению рядом стоящего оборудования и даже обслуживающего персонала. При этом ущерб от возникшего пожара, как правило, существенно превышает стоимость поврежденного ВМЭО.

Все это свидетельствует о необходимости обеспечения взрывобезопасности ВМЭО.

Взрывобезопасным считается оборудование [2, c. 3,7$]$, в котором при возникновении взрыва предотвращается воздействие на людей вызываемых им опасных и вредных факторов и обеспечивается сохранение материальных ценностей. Оборудование считается взрывозащищенным, если при его эксплуатации приняты дополнительные мероприятия, предотвращающие воздействие на обслуживающий персонал опасных и вредных факторов взрыва и обеспечивающие сохранение рядом установленного оборудования.

Одно из главных препятствий на пути создания взрывобезопасных конструкций ВМЭО - отсутствие эффективных и доступных методов испытаний, позволяющих разрабатывать усовершенствованные конструкции ВМЭО.

В последнее время заказчики трансформаторов требуют обеспечить взрывозащищенность аппаратов, т.е. исключить его подрыв с разбрасыванием частей не далее чем на 5 м.

Приведенные данные свидетельствуют о существовании проблемы в обеспечении взрывобезопасности и взрывозащищенности оборудования, при этом применяемая в настоящее время методика испытаний [3, с. 43-46] требует создания электрической дуги с энергией до 50 МДж, возникает необходимость использования мощных источников энергии на основе ударных генераторов или ударных трансформаторов. Подобные испытания являются весьма дорогими. Поэтому рассмотрена принципиальная возможность моделирования воздействия дугового разряда на ВМЭО с помощью 
химической энергии взрывчатых веществ (BВ) на основе аммонита 6ЖВ [4, с. 163-169].

\section{Цель работы}

Разработать новый метод испытаний трансформаторов и провести с его помощью испытания на взрывозащищенность трансформатора тока ТФРМ-330Б-У1 с целью подтверждения механической прочности покрышки и внешних элементов конструкции при гидроударе (работоспособность разгрузочных устройств в составе трансформатора тока при коротком замыкании внутри трансформатора тока), в котором имитация короткого замыкания в трансформаторе производится с помощью навески ВВ расположенной в верхней части трансформатора.

\section{Основная часть}

Работа по испытаниям на взрывозащищенность трансформатора тока ТФРМ-З30Б-У1 проводилась совместно с ОАО «Запорожский завод» высоковольтной аппаратуры». Испытаниям подвергался измерительный трансформатор (рис. 1), представляющий собой аппарат с фарфоровым изолятором массой 3070 кг, содержащий в качестве передающей среды 700 кг трансформаторного масла марки «Nytro-11GX». Заводом разработано собственное разгрузочное устройство и приобретены разгрузочные мембраны фирмы Elfab производства Великобритания, позволяющее снять давление в аппарате при коротком замыкании и направить выброс масла в требуемом направлении. Мембраны установлены в верхней части трансформатора с двух противоположных сторон, двух типоразмеров (рис. 2).

При испытаниях на взрывобезопасность необходимо знать параметры дугового разряда, возникающего в трансформаторе при коротком замыкании.

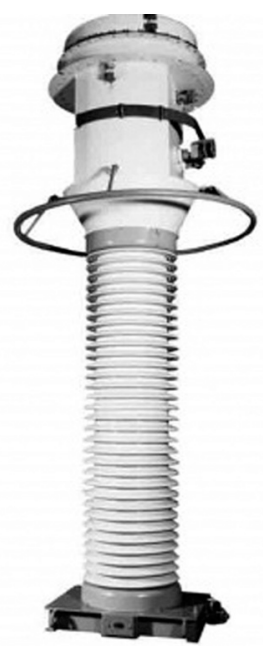

Рис. 1. Общий видтрансформатора ТФРМ-330Б-У1

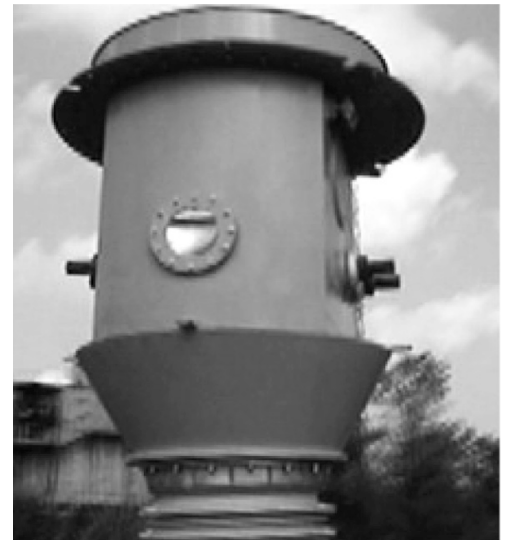

Рис. 2. Верхняя часть трансформатора с разгрузочными мембранами

Масштаб силового воздействия дугового разряда на корпус определяется полной энергией дуги и длительностью ее горения. Продолжительность горения дугового разряда зависит, главным образом, от скорости срабатывания защитных устройств.

Условия срабатывания клапана сброса при прохождении через трансформатор токов короткого замыкания (КЗ) для трансформатора данного типа следующие:

- ток $I_{\text {кз }} \approx 40000 \mathrm{~A}$;

- напряжение на дуге при прохождении тока К $3 U_{\text {Кз }} \approx 36 \mathrm{~B}$;

- время прохождения тока К $3 t_{\text {Кз }} \approx 0,3 \mathrm{c}$.

Следовательно, энергия, которая будет выделена при прохождении КЗ, можно определить по формуле

$$
A=I_{\text {Кз }} \cdot U_{\text {Кз }} \cdot t_{\text {Кз }} \cdot
$$

Зная величину энергии, выделяемой 1 кг тротила [4, с. 163-169], можно определить тротиловый эквивалент, энергия при сжигании которого равна энергии выделяемой дуговым разрядом при коротком замыкании

$$
K_{T}=\frac{A}{A_{T}},
$$

где $A_{T}$ - энергия, выделяемая 1 кг тротила, $A_{T}=$ $=4.61210^{9}$ Дж/кг.

Работа по проведению испытаний трансформатора была разбита на три этапа:

- определение возможности подрыва заряда малой мощности (с малым критическим диаметром) в водной среде;

- испытания бака (верхней части трансформатора) заполненного водой;

- испытания рабочего измерительного трансформатора тока ТФРМ-З30Б-У1, заполненного трансформаторным маслом с разгрузочными устройствами (мембраны, изготовленные ОАО «Запорожский завод» высоковольтной аппаратуры и поставляемые фирмой Elfab Великобритания).

На первом этапе испытаний применялся аммонит марки 6ЖВ массой 100 грамм с критическим 

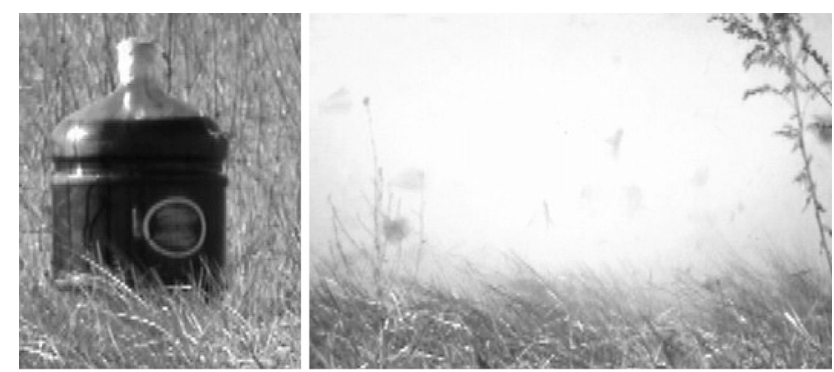

Рис. 3. Подрыв заряда аммонита 6ЖВ в емкости с отработанным трансформаторным маслом

диаметром заряда ВВ 10 мм. В качестве передающей среды использовалась отработанное трансформаторное масло (рис. 3). Заряд размещался посередине емкости.

На втором этапе были проведены испытания верхней части трансформатора (рис. 4) путем размещения и подрыва внутри бака заряда аммонита марки 6ЖВ массой 113 грамм.

В качестве передающей среды внутри бака была использована вода, а верхняя часть бака объемом 150 литров была заправлена трансформаторным маслом. Емкость была выполнена без разгрузочных мембран. Заряд размещался внутри емкости в средней части в месте вероятного появления дугового разряда при коротком замыкании (рис. 5).

Результаты испытаний верхней части бака (рис. 4) показали следующее:

- верхняя крышка сорвана со всех болтов, поднята взрывом до 10 м в высоту, упала рядом с баком на расстоянии около 2 м;

- вертикальные швы в количестве 3 шт. из 4 надорваны;

- стенки бака деформированы.

Испытания данным зарядам показали разрушение верхней части трансформатора соизмеримые с разрушениями от дугового разряда при внутрен-

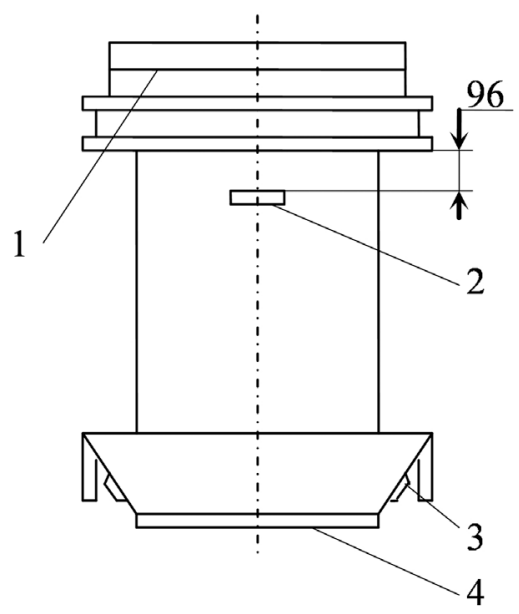

Рис. 5. Место размещения заряда в верхнем баке трансформатора:

1 - уровень масла; 2 - заряд; 3 - разгрузочные клапана; 4 - заглушка
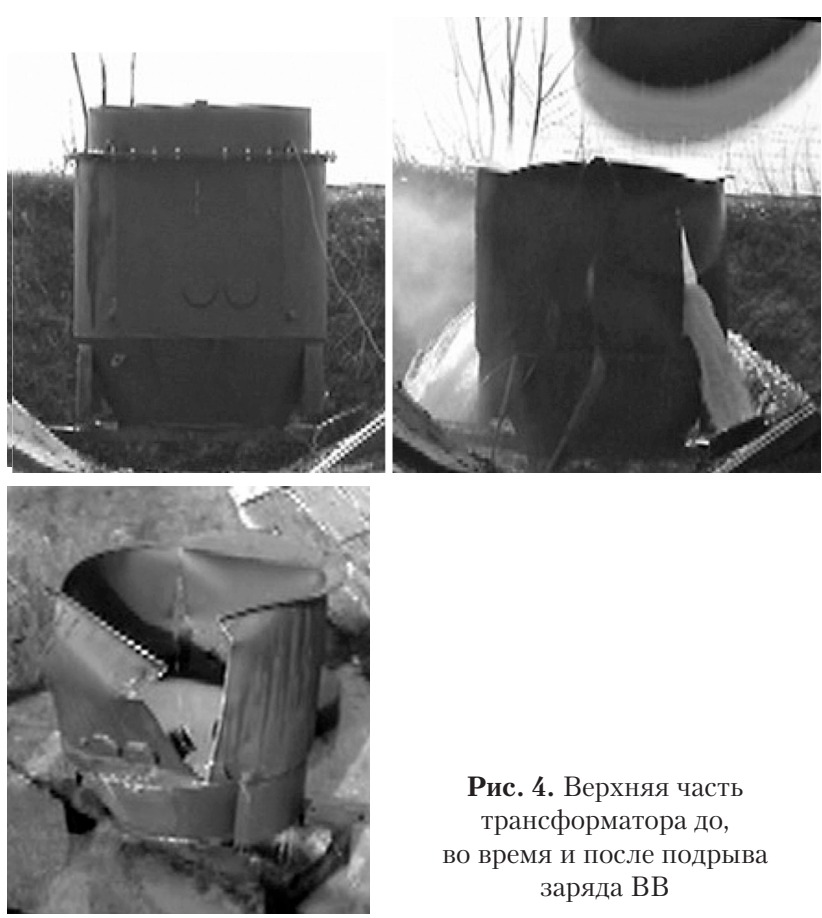

Рис. 4. Верхняя часть трансформатора до, во время и после подрыва заряда ВВ

нем коротком замыкании, что подтверждает правильный выбор ВВ.

На третьем этапе объектом испытаний был измерительный трансформатор тока ТФРМ-330Б-У1 с армированной покрышкой из смеси С130 изготовленный на ОАО «З3ВА» (рис. 6). В испытуемом трансформаторе в качестве передающей среды было использовано трансформаторное масло марки «Nytro-11GX». В качестве навески взрывчатого вещества была использована навеска аммонита марки 6ЖВ массой 50 грамм. Расчетное давление,

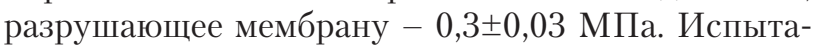
ния проводились на специально подготовленной площадке экспериментально-промышленной базы сварки взрывом ГП «КБ «Южное» имени Янгеля». При этом осуществлялась видеосъемка.

В качестве разгрузочного устройства использовались мембраны, изготовленные ОАО «З3ВА» и

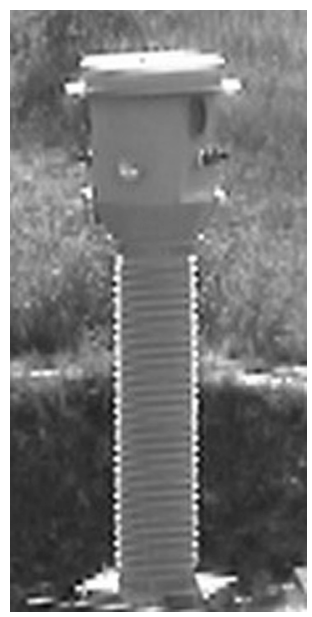

Рис. 6. Испытываемый трансформатор ТФРМ-330Б-У1 


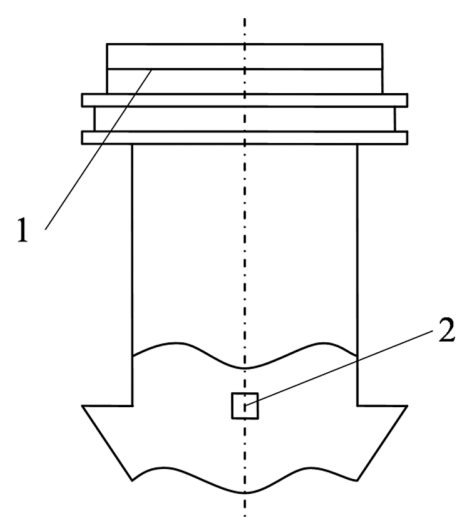

Рис. 7. Место установки заряда в трансформаторе: 1 - уровень масла; 2 - заряд

приобретенные у фирмы Elfab Великобритания (рис. 2), которые практически не снизили прочность бака трансформатора. Заряд устанавливали вблизи с фарфоровым изолятором в месте вероятного возникновения максимального дугового разряда при коротком замыкании (рис. 7).

В результате испытаний отмечено следующее:

- сработали разгрузочные мембраны Elfab (Великобритания) (рис. 8);

- разброс струи масла не превысил 3 м по радиусу (рис. 9);

- произошла разгерметизация между фланцем покрышки и маслорасширителем из-за нарушения уплотнения между ними (рис. 10);

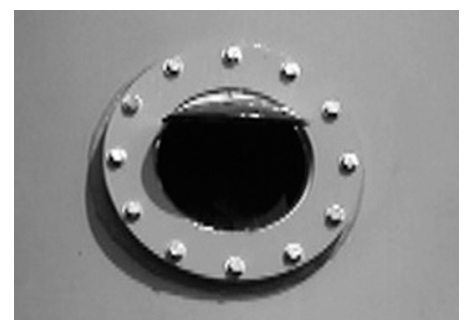

Рис. 8. Разгрузочная мембрана фирмы «Elfab» (Великобритания) после испытаний

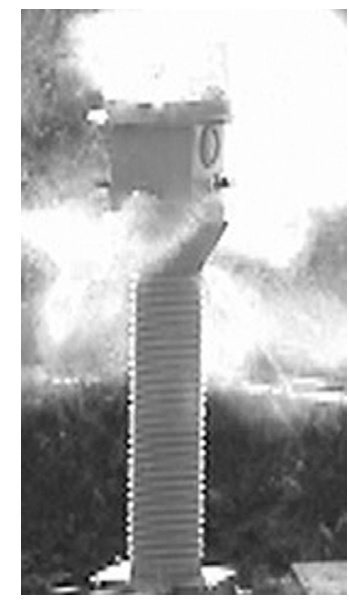

Рис. 9. Разброс струи масла после подрыва заряда взрывчатого вещества

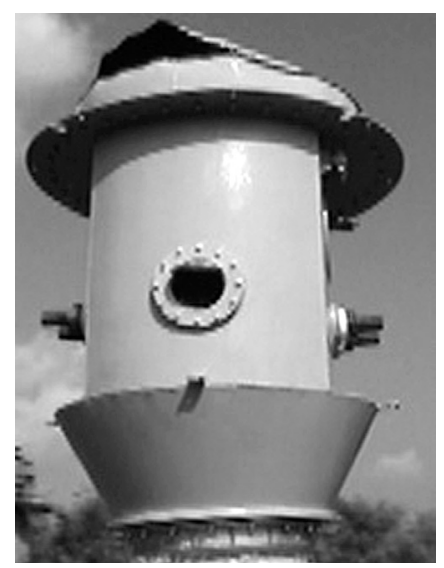

Рис. 10. Верхняя часть трансформатора после испытаний

- целостность покрышки не нарушена;

- произошел подрыв по сварочному шву и деформация верхней крышки (рис. 10) и др.

Эксперимент показал, что если бы сработали все четыре мембраны, то трансформатор не имел бы никаких разрушений, но даже при двух сработавших мембранах трансформатор при перечисленных разрушениях можно считать взрывозащищенным.

\section{Выводы}

По результатам работ можно сделать следующие выводы:

- проведенные испытания позволяют сформулировать предварительные требования к системе защиты трансформаторов серии ТФРМ от воздействия дугового разряда при коротком замыкании;

- разработанный метод испытаний на взрывозащищенность с помощью взрывчатых материалов можно применять и для других типов трансформаторов;

- трансформаторы тока серии ТФРМ изготовленные $\mathrm{AOA} \mathrm{«33ВА»} \mathrm{являются} \mathrm{взрывозащищен-}$ ными при условии применения разгрузочных мембран и фарфоровой покрышки изготовленной из смеси С130.

\section{Литература}

[1] Положение о технической политике ОАО «ФСК ЕЭС». - М.: - 2006. - 73 стр.

[2] ГОСТ 12.1.010 - 76 «Система стандартов безопасности труда. Взрывобезопасность. Общие требования». - М.: ИПК Издательство стандартов. - 2002. - 7 стр.

[3] Дарьян Л.А., Дементьев Ю.А., Ефремов В.П. и др. / Альтернативный метод оценки взрывобезопасности и взрывозащищенности высоковольтного маслонаполненного электрооборудования // Электро. 2009. - № 5. - С. 43-46.

[4] Дубнов Л.В., Кудинов В.М., Лебедь С.Г., Романов А.И. Аммониты для сварочных работ // физико-химические и взрывные процессы в машиностроении. Москва: МВТУ имени Н.Э. Баумана, - 1973. C. $163-169$ 
Pakhomov S. N., Potapov A. M., Reznichenko V. I. , Mostipan S.Y.

Yuzhnoye, State-owned Design Office named after M. K. Yangel. Ukraine, Dnipro

\section{TEST OF THE PROTECTION SYSTEM FOR OIL-FILLED CURRENT TRANSFORMERS FROM THE EFFECT OF ARC DISCHARGE IN CASE OF A SHORT-CIRCUIT OF THE EXPLOSION ENERGY}

The result of testing of high-voltage transformers TFRM with discharge relief valves and reinforced porcelain tire, in which transformer oil is used as an inner insulation, by blasting an explosive, simulating a shortcircuit inside the current transformer have been considered. [dx.doi.org/10.29010/081.2]

Keywords: oil-filled current transformer; explosion proof; relief diaphragm.

\section{References}

[1] Regulations on the technical policy of FGC UES. - M.: - 2006. - 73 p.

[2] GOST 12.1.010-76 "Occupational safety standards system. Explosion proof. General requirements". - M.: IPK Publishing house of standards. - 2002. - $7 \mathrm{p}$

[3] Daryan LA, Dementiev Yu.A., Efremov VP et al. / Alternative method for estimating the explosion-proof and explosion-proof high-voltage oil-filled electrical equipment // Electro. - 2009. - № 5. - P. 43 - 46.

[4] Dubnov LV, Kudinov VM, Lebed SG, Romanov AI Ammonites for welding works // physical and chemical and explosive processes in mechanical engineering. - Moscow: MVTU named after N.E. Bauman, - 1973. - With. 163-169. 